\title{
Etika Bisnis Rasulullah SAW Sebagai Pelaku Usaha Sukses dalam Persfektif Maqashid Syariah
}

\author{
Neni Hardiati $^{\left.1^{*}\right)}$, Ayi Yunus Rusyana ${ }^{2)}$ \\ ${ }^{1,2}$ Program Studi Magister Hukum Ekonomi Syariah, Universitas Islam Negeri Sunan Gunung Djati Bandung \\ *Email korespondensi: nenihardiati@gmail.com
}

This study aims to review the business ethics carried out by Rasulullah SAW in accordance with the objectives of maqashid sharia. The writing of this journal article uses qualitative research, in this article, the literature study conducted by the author is to search various written sources, whether in the form of books, archives, magazines, articles, and journals, or documents relevant to the problem. reviewed from the latest journals that discuss the business ethics carried out by the Prophet Muhammad which is in accordance with the objectives of maqashid sharia. Based on the above discussion, what is obtained is that business actors must follow business ethics as exemplified by the Prophet. However, there are several aspects that must be fulfilled involving some irresponsible parties, such as dishonesty, not protecting consumer rights, friendly buyers or using disrespectful language, buyers who do not protect the rights of patrons, and business actors who are not responsible for customers and pelapak quickly and precisely. The implementation of maqashid sharia, four safeguards of which can protect consumers from their rights.

Keywords: Business Ethics, Business Personnel, Perspective, Maqashid Syariah

Saran sitasi: Hardiati, N., \& Rusyana, A. Y. (2021). Etika Bisnis Rasulullah SAW Sebagai Pelaku Usaha Sukses dalam Persfektif Maqashid Syariah. Jurnal Ilmiah Ekonomi Islam, 7(01), 513-518. doi:http://dx.doi.org/10.29040/jiei.v7i1.1862

DOI: http://dx.doi.org/10.29040/jiei.v7i1.1862

\section{PENDAHULUAN}

Manusia sebagai makhluk sosial manusia tak terlepas dari hubungan untuk saling berinteraksi sebab manusia memiliki keharusan sebagai khalifah di dunia dalam menciptakan kemaslahatan. Salah satu cara mwujudkan kemaslahatan tersebut yakni dengan kegiatan bisnis. Etika bisnis dalam islam menuntut perilaku yang baik, sebab saat ini banyak terjadi kerusakan moral yang makin meluas pada perusahaan. Kuatnya pemberdayaan etika yang unggul mencerminkan nama baik perusahaan. (Naranjo, 2014).

Saat ini banyak pelaku bisnis yang hanya mementingkan tujuan guna mendapat keuntungan dengan menghalalkan banyak cara (Muhammad Saifullah, 2011) bahkan tak jarang mereka mengabaikan etika bisnis maupun tnaggungjawa sosial. Dalam islam umat muslim telah mengenal Nabi Muhammad SAW sebagai pelaku usaha yang sukses. Kesuksesan beliau tak terlepas dari keteladanan dan kebijaksanaan sebagai pelaku usaha sejati. Agar dalam pelaksanaannya selaras untuk menghasilkan kebermanfaatan, maka kita wajib untuk melaksanakan nilai-nilai etika bisnis (Hamzah et al., 2017). Dalam usaha meperoleh rizki yang halal merupakan sebuah kewajiban. Hal tersebut akan erdampak pada kehidupan sosial (Antonio, 2018).

Hingga saat ini perkembangan ekonomi tak terlepas dari sejarah islam. Ekonomi merupakan bagian yang tak terpisah dari kegiatan manusia. (syahrizal, 2018). Dalam usaha apapun harus selalu diiringi dengan nilai-nilai ketuhanan serta apapun yang dilakukan harus bersumer dari sebuah mata air kehidupan atau biasa disebut dengan maqashid syariah.

(Wulandari, 2017), menyatakan bahwa para ulama klasik, seperti Al-Syaitibi memutuskan tingkatan maqashid syariah terbagi menjadi 3 yakni al maqashid dharuriat, al maqashid hajiyyat, al maqashid tahsyiniyat. Diantara ketiga al maqashid tersebut 
yakni yang pertama agar dapat memelihara kebutuhan utama atau primer sebab bila kebutuhan ini tidak tercukupi dapat mengancam ketentraman maupun keselamatan baik di dunia maupun di akhirat yakni ada 5 yang dapat mengancamnya ialah pemeliharaan pada agama, pada jiwa, pada akal, terhadap keturunanan dan pemeliharaan pada harta. lalu yang kedua sebagai kebutuhan sekuder yakni bila tidak tercukupi akan mengancam kemananan sehingggga akan timbul kesukaran namun bila terpenuhi akan membuat kemudahan bagi manusia. Kemudian yang terakhir sebagai suatu kebutuhan pelengkap, karena sebagai pelengakp tentunya tidak akan mengancam kemananan ataupun menyebabkan kesukaran. Namun hal ini akan menjadi penyempuran dari kebutuhan primer maupun sekuder, yakni kebiasaan, perilaku, aturan atau norma yang berlaku dalam sosial kemasyarakatan. Sehingga maqasid syariah ini penting diterapkan dalam perilaku bisnis.

(Wulandari et al., 2017) dalam penelitiannya memperoleh hasil Rasullullah SAW telah menerapkan etika bisnis seagaimana dalam maqashid syariah dengan empat sistem proteksi guna melindungi hak pelanggan. Ia menyarankan rekomendasi harus diterapkan serta memaparkannya agar dapat memenuhi prinsip syariah dan regulasi.

Hasil penelitian (Farida, 2017) menunjukkan bahwa dalam maqhasid syariah, perlindungan hukum bagi pelaku UMKM di tengah pasar bebas sangat diperlukan selama tidak menghilangkan dan mengurangi prinsip-prinsip syariah dalam bermuamalah. Selain itu, perlindungan tersebut sangat penting karena untuk kemaslahatan bagi pelaku usaha. (Nabilah et al., 2019) dalam penelitiannya menyimpulkan ahwa penggungkapan etika berdasarkan perspektif maqashid syariah belum di ungkap secara keseluruhan, beberapa kategori ada yang belum diungkap bahkan ada yang tidak diungkap sama sekali.

Sementara itu menurut (Ruslang et al., 2020) terlaksananya etika bisnis yang sesuai dengan maqashid syariah membawa implikasi yang baik terhadap keberlangsungan bisnis Shopee, pembeli yang semakin meningkat kepercayaan terhadap shopee sehingga mereka loyal untuk terus belanja di Shopee. Demikian juga seller semakin setia menjual di Shopee karena jumlah pembeli semakin bertambah yang berpengaruh terhadap keuntungan.

Berdasarakan latar belakang masalah di atas, maka penelitian ini bertujuan untuk mengulas tentang bisnis etika yang dilakukan Rasulullah SAW yang sesuai dengan tujuan maqashid syariah.

\section{Rumusan Masalah}

1. Bagaimana etika bisnis Nabi Muhammad SAW?

2. Bagaimana Tinjauan nilai-nilai maqashid Syariah dalam etika bisnis Rasulullah SAW?

\section{METODE PENELITIAN}

Penulisan artikel jurnal ini menggunakan penelitian kualitatif, dengan pendekatan studi kepustakaan. (Sugiyono, 2015) menyatakan bahwa studi kepustakaan adalah cara yang dipakai untuk menghimpun data-data atau sumber-sumber yang berhubungan dengan topik yang diangkat dalam suatu penelitian. Dalam penulisan artikel ini, studi literatur yang dilakukan oleh penulis yaitu dengan melakukan pencarian terhadap berbagai sumber tertulis, baik berupa buku-buku, arsip, majalah, artikel, dan jurnal, atau dokumen-dokumen yang relevan dengan permasalahan yang dikaji dari Jurnal-jurnal terbaru yang membahas tentang etika bisnis yang dilakukan Rasulullah SAW yang sesuai dengan tujuan maqashid syariah.Kegiatan penunjang yang dilakukan dalam melakukan kajian literature ini meliputi mencari, membaca, dan menelaah pendapat - pendapat dari para ahli dan bahan pustaka yang memuat teori-teori yang relevan.Sehingga dengan metode tersebut dapat digali nilai-nilai filosifis dalam pengembangan ekonomi Islam dalam bidang produksi produk halal. Metodologi yang digunakan yakni metodologi studi Islam, melalui proses ilmiah, tepat dan tuntas dalam memaknai ajaran Islam secara menyeluruh dari berbagai aspek sumber, pemahaman ajarannya pada sumber sejarah (Hakim \& Mubarok, 2017)

\section{PEMBAHASAN}

\subsection{Etika Bisnis Rasulullah SAW}

\section{a. Perjalanan Bisnis Rasulullah SAW}

(Koni, 2017), menyatakan dalam sejarah dikisahkan kalau semenjak kecil Nabi Muhammad SAW mengembalakan ternak para peternak kambing. Jumlah ternaknya juga terbilang tidak sedikit, ratusan. Secara tidak langsung sebagai media pendidikan pembelajaran bisnis awal beliau, ialah gimana mengorganisasi, memanage, serta mengelola seluruh suatu yang dipercayakan kepadanya. Sehingga dia berkembang jadi pribadi yang kredibel, bertanggung jawab, cermat, empati, terbuka, mandiri, berani, gampang menyesuaikan 
diri, tabah, lugas, visioner, dll dalam usia yang masih sangat muda. Beliau sering turut dalam lawatan- lawtan bisnis ke negara- negaraorang sebelah yang sekarang dikenal dengan nama, Irak, Yordania, Bahrain, Suriah, serta Yaman. Dikala itulah eliau sudah belajar bagaimana sebagai seseorang eksportir handalsekaligus menyandang posisi sebagai eksekutif muda di masa itu.

Beranjak dewasa, Nabi Muhammad SAW kian mantap memilah karirnya bagaikan pebisis. Beliau mengawalinya dengan jadi seseorang manajer perdagangan yang mencerna modal investor dengan sistem untuk hasil. Serta memanglah, berkat keahlian dandidikan bisnis sejak kecil, para investor senantiasa merasa puas hendak hasil yang dicapai olehNabi Muhammad SAW. Dalam menggapai kesuksesan semacam itu pastinya beliau mempraktikkan satu prinsip serta strategi manajemen bisnis yang sangat profesional. Prinsip- prinsipnya antara lain: jujur, setia, serta handal. Serta ini mendadak jadi satu teladan etika bisnis yang ditiru oleh segenap bangsa Arab. Kita ketahui sendiri keadaan bangsa Arab dikala itu semacam apa. Terlebih, kala itu Muhammad mengutamakan customer satisfaction, excellence service, kompetensi, efisiensi, tranparansi dan persaingan yang sehat serta kompetitif. Hal ini menjadi fondasi etika bisnis serta style manajemen yang luar biasa kepada bangsa Arab, sistem bisnis yang dibangunnya telah tertata sedemikian rupa, sampai tanpa kedatangan dirinya juga bisnis senantiasa berjalan baik, kalua istilah saat ini bisa jadi dapat diistilahkan dengan passive income.

\section{b. Etika Bisnis dalam studi Islam}

(Desy Astrid Anindya, 2017), menyatakan kata etika bersumber dari bahasa latin "etos" yang bermakna kebiasaan persamaannya yakni moral, pun berasal dari bahasa yang sama mores ialah jamak dari mufradat "khulud" yang memiliki pengertian budi pekerti. Bisnis ialah suatu organisasi yang melangsungkan kegiatan produksi dan kontribusi penjualan barang maupun jasa yang diharapkan oleh costumer dalam memperoleh penghasilan(Lubis, 2018).

Dalam studi Islam sering disebut al-khuluq merupakan bentuk tunggal yang ada dalam alquran yakni pada ayat 4 surat al-Qalam yang memilki nilai konsederans atas ditetapkan Nabi Muhammad SAW menjadi Rasul. Yang artinya: "Sesungguhnya engkau Muhammad berada di atas budi pekerti yang besar". Dalam Islam potensi baik lebih di dahulukan ketimbang potensi dalam perilaku kejahatan. Sehingga perilaku bisnis mengandung asas-asas etika yang dibedakan antara yang buruk maupun yang baik untuk menetapkan prinsip-prinsip umum yang dapat membenarkan dalam dunia usaha(Rahmat, 2017).

(Amalia, 2012), menyatakan bahwa etika bisnis Islam ialah berbagai perilaku etis dalam Islam disebut dengan Akhlak al islamyah yang dikemas melalui nilai-niali syariah yang lebih mendahulukan halal maupun haram. Etika bisnis dalam Islam yakni sekumpulan peraturan yang melaksanakan usaha seperti jika pedangang harus mengetahui larangan maupun yang di anjurkan sebab dalam Al-Quran pedagang tidak boleh mengurangi timbangan harus sesuai

dengan adanya (Karishma W \& Widiastuti, 2017). Pribadi yang jujur, adil, benar, merdeka, bahagia, maupun cinta kasih merupakan nilainilai yang di dorong oleh nilai etik, ahlak maupun moral dari manusia. Sebab hakikat manusia seutuhnya ialah melaksanakan nilai-nilai dari etika. Adapun yang menjadi sumber segala nilai dalam sendi kehidupan yakni Al-Qu'ran dan hadist. Dua pedoman inilah yang dapat menuntun kita dalam berperilaku dalam kegiatan bisnis (Desy Astrid Anindya, 2017). Syahatah dan Siddiq dalam menyatakan bahwa dalam bermuamalah di butuhkan perilaku yang baik, agar tidak terjadi kerusakan ahkhak yang luas pada usaha. Kemudian dengan etika yang baik akan mendapatkan nama baik usaha (Naranjo, 2014).

\section{c. Etika Bisnis Nabi Muhammad SAW}

Keberhasilan Rasulullah SAW dalam membangun usaha terlihat darikepribadiannya yang berani. Bahkan kemampuan mengatur bisnisnya sehingga membawa dagangan Khadijah dan hanya dibarengi karyawannya yakni Maisarah. Beliau sangat bertanggungjawab yang sempurna atas semua dagangan miliki Khadijh.(Karimah, 2016). Supaya usaha yang kita bangun dapat memperoleh kebaikan dalam hidup serta berjalan harmonis seperti Rasulullah SAW. Hal ini mesti kita laksanakan dengan 


\section{Jurnal Ilmiah Ekonomi Islam, 7(01), 2021, 516}

perilaku-perilaku yang baik. Salah satu teladan yang menjadi acuan umat muslim dalam membangun bisnis terutama dalam hal perilaku kita perlu merujuk kepada tokoh yang paling agung teladan umat muslim di muka bumi, yakni Nabi Muhammad SAW.

(Baidowi, 2010), menyatakan dalam menjalankan bisnisnya Nabi saw memiliki etika berikut ini:

1) Kejujuran

Kejujuran ini menjadi suatu hal yang sangat penting dalam berbisnis sebagai sebuah kepercayaan. Beliau selalu berperilaku jujur dalam bermuamlah. Hal ini sesuai sabda Rasul yakni "siapapun yang membuat penipuan itu dari golongan kami". (H.R. AlQuzwani). Beliau juag bersabda " tidak baik seorang pedanagn yang memiliki aib, kecuali ia menerangkan aibnya.

2) Tolong menolong ataupun memberikan kebermanfaatan terhadap orang lain

Pelaku usaha sudah seharusnya tidak hanya memikirkan keuntungan semata namun harus memliki perilaku yang ta'awun atau tolong menolong dalam hal kebaikan terutama dalam usaha.

3) Dilaranggharar baik takaran, ukuraan, maupunpenimbangan harus sesuai.

Dalam berbisnis penimbangan yang sesuai adanay dan tepat wajib diutamakan. Sebagaimana Firman Allah: "Celakalah untuk orang yang tidak jujur, yakni orang yang jika menerima takaran dari yang lain, mereka meminta dicukupi, dan jika mereka membuat takaran atau penimbangan sesuai bagi yang lain, mereka mengurangi" (QS 83:112).

4) Dilarang mengejek usahayang lain, supaya membeli terhadapnya.

Rasulullah SAW bersabda, "Janganlah seseorang di antra kalian menjual memiliki tujuan dalam menjelekkan apa yang dijual yang lainnya," (H.R. Muttafaq 'alaih). K

5) Dilarang menumpuk-numpuk harta

Melakukan menumpuk-numpuk harta pada masa tetentu yang memilki tujuan supaya harganya meningkat kemudia dapat keuntungan besar yang di dapatkan. Dalam kegiatan ini Nabi sangat tidak membolehkan etika bisnis seperti ini.

6) Dilarang monopoli
Menguasai suatu hak milik untuk memperoleh keuntunagn ini merupakan sifat buruk dari kapitalis. Hal ini sangat tidak diperbolehkan oleh Islam

7) Komoditas yang diperdagangkan harus halal dan suci bukan barang-barang yang terlarang, sesuai sabda Rasulullah SAW "Sesungguhnay Allah melarang bentuk usaha miras, bangkai, babi, maupun patung (H.R. Jabir).

8) Kegiatan usaha yang dilakukan harus terhindar dari riba. Sebagaimana firman Allah "Hai orang-orang yang beriman, maka lupakan sisa-sisa riba bila kamu beriman". Sebab itu, Allah dan Rasul mengabarkan perang pada riba.

9) Dalam suatu usaha dilakukan dengan dasar saling ridho tanpa dipaksa. Sesuai firman Allah, "Hai orang yang beriman, tidak boleh kamu saling memakan harta sesame melalui jalan yang bathil, kecuali melalui cara usaha yang saling suka dinatara kamu.

10) Membayarkan gaji sebelum iakering keringat karyawan. Nabi Muhammad saw. bersabda, "Berikanlah upah pada karyawan, sebelum ia kering keringatnya." Hadist ini menjelaskan bahwasanya dilarang menunda-nunda upah pegawai. Pembayaran upah mesti sesuai pada kerja yang dilaksanakan.

Implementasi etika bisnis berdasarkan teori yang telah dijelaskan di atas, ada beberapa sikap yang telah dicontohkan oleh Rasulullah saw dalam melakukan perdagangan. Sikap-sikap itu antara lain jujur, adil, ramah, cakap, senang membantu pelanggan, menjaga hak-hak konsumen, dan tidak menjelekkan bisnis orang lain. Jika dikaitkan dengan teori etika bisnis Islam diatas, maka dapat terlihat bahwa produk yang dipasarkan oleh pelaku usaha, jika mengikuti ketentuan yang ada, tidak ada yang mengandung unsur pelanggaran etika. Karena dalam ketentuannya, barang-barang yang akan dijual tidak boleh sesuatu yang dapat mengancam kehidupan orang lain. Secara umum, sistem pembayaran yang telah ditetapkan oleh pelaku usaha harus memudahkan bagi pembeli dan penjual. Namun terkadang ketika terjadi masalah pada sistem pembayaran yang diberikan oleh pembeli kepada penjual masih tersimpan dalam sistem, dan belum dapat secara langsung diterima oleh penjual. 


\subsection{Maqashid Syariah \\ Pengertian Maqashid Syariah}

(Mingka, 2013), menyatakan bahwa maqasid syariah ialah tujuan dalam mewujudkan kemaslahatan manusia di muka bumi maupun akhirat. Secara terminologi, maqasid syariah terbagi dalam dua kata yakni maqasid dan Syariah.(Toriquddin, 2010) menyatkan bahwa maqasid bermakna tujuan dan syariah ialah ajaran, aturan, dan hukum Allah yang diwahyukan pada hambanya dalam mencapai falah di dunia maupun akhirat. Istilah maqasid syariah di viralkan oleh Imam Syatibi. Imam Syatibi yang memiliki julukan bapak maqashid Syariah, yang membuat rumusan dan konsep yang jelas, sistematis, dan menyeluruh. Hal ini memiliki tujuan kemaslahatan umat. Dalam (Mingka, 2013) dan(Dewi \& Farida, 2019), Imam Syatibi membedakan ke dalam tiga bagian:

a. Dharuriyat adalah tingkat keperluan yang paling utama sering disebut kebutuhan primer. Sebab jika kebutuhan ini tidak tercukupimenyebabkan ketentraman hidup manusia di dunia ataupun di akhirat nanti. Al-Syatibi mengemukakan terdapat lima hal yang masuk di dalam kategori ini, yakni penyelematanpada agama, penyelamatan pada jiwa, penyelamtan pada akal, penyelamatan pada kehormatan maupun keturunan, serta penyelamatanpada harta.

b. Hajiyat adalah tingkatan kebutuhan yang sekunder, sehingga bila tidak terwujud tidak sampai mengancam ketentramna nya, namun dapat menyebabkan kesusahan. Hal ini Islam ingin menghilangkan semua kesulitan itu dalam kepedulian dari Syariah Islam sebagai wujud dari kebutuhan ini.

c. Tahsiniyat adalah tingkatan suatu kebutuhan yang bila tidak tercukupi tak akan mengancam dari dari lima pokok yang ada dalam dahuriyat sehingga tidak menyebabkan kesukaran. Tingkat keperluan ini ini ialah pelengkap saja. Al-Syatibi, menyatakan hal-hal yang menjadi kepatutan dalam adat istiadat, menjauhkan dari hal yang tidak elok dipandang mata, maupun berhias melalui keindahan yang sesuai sama tuntutan akhlak dan moral.

Dalam implementasinya tiga tingkatan maqashid syariah, yaitu tahsiniyyat, hajiyyat, dan dharuriyyat akan memiliki kaitan dari tiga inti penelitian ini. Jika kita hubungkan dengan tema penelitian ini, maka etika bisnis memiliki kaitan dengan maqashid tahsiniyat. Sedangkan transaksi jual beli merupakan aktivitas muamalah yang termasuk kedalam maqashid hajiyyat, dan semuanya itu bertujuan untuk melindungi agama, jiwa, akal, keturunan dan harta manusia, yang merupakan maqashid dharuriyyat.

Telah dijelaskan pada subbab implementasi etika bisnis, bahwa marketplace pelaku usaha berupaya untuk menjalankan transaksi sesuai dengan etika bisnis yang dicontohkan oleh Rasulullah SAW. Terlepas dari itu, beberapa kebijakan pelaku usaha bisa lebih disesuaikan dengan keadaan yang ada, yang terkadang hal ini membuat tidak semua pihak dapat menerima. Kemudian sikap adil ditunjukkan oleh pihak pelaku usaha dengan memberikan aturan penggunaan dan sanksi yang berlaku sama bagi seluruh anggota. Tidak menutup kemungkinan sikap adil yang diberikan oleh pelaku usaha tidak dapat dirasakan oleh semua pihak. Keramahan, kecakapan dan senang membantu orang yang dilakukan oleh pelaku usaha terlihat dari pelayananan yang dapat membantu pembeli ketika mengalami kesulitan dalam melakukan transaksi dengan menggunakan bahasa yang baik. Tetapi, tidak semua sistem sempurna.

Menjaga hak konsumen dapat terlihat ketika para pembeli diberikan khiyar atau hak pilih produk sebelum mengambil keputusan. Sebelumnya, pembeli diberikan informasi mengenai produk yang tersedia. Sehingga pembeli dapat memilih dengan baik. Setelah transaksi berjalan dengan baik dan barang sudah diterima oleh pembeli, hak pembeli selanjutnya ialah memberikan timbal balik berupa feedback negatif atau positif kepada penjual sesuai dengan yang diterima oleh pembeli.

Jika dikaitkan dengan fenomena yang terjadi pada pelaku usaha, penjagaan terhadap agama dapat diketegorikan mampu melindungi hak nonmuslim dan muslim. Karena dalam melakukan transaksi, tidak ada perbedaan yang membuat suatu golongan agama merasa didiskriminasikan. Penjagaan terhadap jiwa (hifz an nafs) berkaitan dengan penjagaan hak-hak manusia secara komprehensif. Hak pertama yang diperhatikan dalam Islam adalah hak hidup, hak yang disucikan dan tidak boleh dihancurkan kemuliannya. Seperti dalam sabda Rasulullah SAW yang diriwayatkan oleh Al Bukhari dari jalur Abu Hurairah, "orang yang mencekik dirinya, dia akan mencekik dirinya di neraka. Dan orang yang menusuk dirinya akan menusuk diri di neraka. Dan orang yang menembus (perutnya dengan pisau), akan menembusnya di neraka.

Dalam kaitannya dengan fenomena yang terjadi pada pelaku usaha, penjagaan terhadap jiwa dapat terlihat dari ketentuan barang yang diperbolehkan untuk masuk di pelaku usaha. Seperti tidak menerima 


\section{Jurnal Ilmiah Ekonomi Islam, 7(01), 2021, 518}

obat-obat terlarang, benda tajam, organ manusia, barang yang dapat meledak atau terbakar sendiri, serta barang-barang lain yang tidak diperbolehkan berdasarkan hukum yang berlaku di Indonesia.

\section{KESIMPULAN}

Berdasarkan pembahasan di atas, kesimpulan yang didapatkan adalah bahwa pelaku usaha harus mengikuti etika bisnis yang telah dicontohkan oleh Rasulullah saw. Namun, terdapat beberapa aspek yang harus terpenuhi diakibatkan beberapa pihak yang tidak bertanggung jawab, seperti pelapak yang tidak jujur, pelapak yang tidak menjaga hak konsumen, pembeli yang kurang ramah atau menggunakan bahasa yang kurang sopan, pembeli yang tidak menjaga hak pelapak, dan pelaku usaha yang tidak menanggapi keluhan pelanggan dan pelapak secara cepat dan tepat. Implementasi maqashid syariah, empat penjagaan diantaranya sudah dapat melindungi konsumen dari hak-haknya. Seperti perlindungan terhadap agama, jiwa, akal dan keturunan.

\section{REFERENSI}

Amalia, F. (2012). Implementasi Etika Bisnis Islam Pada Pedagang Di Bazar Madinah Depok. Prosiding Seminas Competitive Advantage, 1(2), $1-33$.

Antonio, M. S. (2018). Ensiklopedia Leadership dan Manajemen Muhammad SAW" The Super Leader Super Manager". Tazkia publishing.

Baidowi, A. (2010). Etika Bisnis Islam Dalam Perspektif Islam. Hukum Islam, 9(1412-3851), 239-250.

Desy Astrid Anindya. (2017). Pengaruh Etika Bisnis Islam terhadap Keuntungan Usaha pada wirausah di desa Delitu kecamatan Delitua. At-Tawassuth, 2, 384-412.

Dewi, V. S., \& Farida. (2019). Maqasid Syariah Sebagai Indikator Pembangunan Sebuah Perguruan Tinggi Islami. Jurnal Ekonomi \& Pembangunan Optimum, 9(1), 73-84.

Farida. (2017). Analisis Pengaruh Penerapan Kinerja Maqasid terhadap Manajemen Risiko pada Perbankan Syariah. XII(2), 171-186.

Hakim, A. A., \& Mubarok, J. (2017). Metodologi Studi Islam. Rosda.

Hamzah, N., Kopromotor, S., \& Wahab, A. (2017). Penerapan Etika Bisnis Pedagang.

Karimah, A. (2016). Melayunya Etika Bisnis Dalam Masyarakat Islam Melayu Nusantara. Wardah, 16(1), 73-83.
Karishma W, Y., \& Widiastuti, T. (2017). Etika Bisnis Islam Dalam Pengelolaan Bisnis di Pesantren Mukmin Mandiri. Jurnal Ekonomi Syariah Teori Dan Terapan, 4(6), 464. https://doi.org/10.20473/vol4iss20176pp464477

Koni, W. (2017). Etika Bisnis Dalam Ekonomi Islam. Al-Buhuts, $\quad$ 13(2), 75-89. https://doi.org/10.30603/ab.v13i2.896

Lubis, A. A. (2018). Analisis Aspek Religiusitas Terhadap Etika Bisnis Pedagang Pasar Muslim Pusat Pasar Kota Medan. Dusturiyah: Jurnal Hukum Islam, Perundang-Undangan Dan Pranata Sosial, 7(1). https://doi.org/10.22373/dusturiyah.v7i1.2339

Mingka, A. (2013). Maqashid Syariah Dalam Ekonomi dan Keuangan Syariah. Jakarta: Iqtishad Publishing.

Muhammad Saifullah. (2011). Etika Bisnis Islami dalam Praktek Bisnis Rasulullah. Journal of Chemical Information and Modeling, 53(9), 1689-1699.

Nabilah, N., Maslichah, M., \& Mawardi, M. C. (2019). PERSPEKTIF MAQASHID SYARIAH PADA PENGUNGKAPAN ETIKA DAN TANGGUNG JAWAB SOSIAL BANK SYARIAH DI INDONESIA. Jurnal Ilmiah Riset Akuntansi, 8(03).

Naranjo, J. (2014). Etos Kerja Pedagang Etnis Madura di Pusat Grosir Surabya ditinjua dari Etika Bisnis Islam. Applied Microbiology and Biotechnology, $85(1)$, 2071-2079. https://doi.org/10.1016/j.bbapap.2013.06.007

Rahmat, B. Z. (2017). Corporate Social Responsibility Dalam Perspektif Etika Bisnis Islam. Amwaluna: Jurnal Ekonomi Dan Keuangan Syariah, 1(1), 98-115. https://doi.org/10.29313/amwaluna.v1i1.2099

Ruslang, R., Kara, M., \& Wahab, A. (2020). Etika Bisnis E-Commerce Shopee Berdasarkan Maqashid Syariah Dalam Mewujudkan Keberlangsungan Bisnis. Jurnal Ilmiah Ekonomi Islam, 6(3), 665-674.

Sugiyono. (2015). Metode penelitian pendidikan. In Jakarta : mitra wacana merdeka (pp. 286-288).

Toriquddin, M. (2010). Teori Maqashid Syariah Persefektif Al-Syaitibi.

Wulandari, D. N. (2017). Etika Bisnis E-Commerce Berdasarkan Maqashid Syariah Pada Marketplace Bukalapak.Com. Jmm Unram Master of Management Journal, 6(1). https://doi.org/10.29303/jmm.v6i1.21

Wulandari, D. N., Santoso, B., \& Athar, H. S. (2017). Etika Bisnis E-Commerce Berdasarkan Maqashid Syariah Pada Marketplace Bukalapak. Com. Jmm Unram-Master of Management Journal, 6(1). 